\title{
MATERIAIS, TÉCNICAS E PROCESSOS DE DESIGN: diretrizes para a implementação de observatório de mudanças
}

\author{
Cyntia Santos Malaguti de Sousa \\ Centro Universitário Senac \\ cyntiamalaguti@uol.com.br
}

\author{
Helena Rugai Bastos \\ Universidade Federal do Rio Grande do Norte, UFRN \\ helenarugai@gmail.com
}

\begin{abstract}
Resumo: $O$ artigo apresenta resultados preliminares do projeto de pesquisa "Cultura material e design: observatório de mudanças", que propõe definir diretrizes para a implementação de um observatório de pesquisa sobre design em Instituição de Ensino Superior em São Paulo. 0 propósito é conceber um núcleo, dotado de instrumentos e métodos, que permitam acompanhar o desenvolvimento de pesquisas e de projetos de design de produto, gráfico e de moda, que priorizem a reflexão sobre uso e transformação de materiais, e sobre os processos de produção. O observatório, como instrumento, na forma de um banco de dados, deve permitir a análise sobre o desenvolvimento do campo do design na instituição e contribuir para novas pesquisas e projetos acadêmicos que abordem estudos sobre cultura material, que articulem a reflexão sobre projetos de design e o uso de materiais e seus processos de transformação, ou que explorem estes aspectos.
\end{abstract}

Palavras-chave: Cultura Material, Observatório, Design, Materiais, Inovação

\begin{abstract}
This article presents the first results of a research project aimed at implementing a Research Observatory in a Brazilian Design School in São Paulo, to cover the fields of product, graphic and fashion design. The Observatory's focus is to monitor the materials and manufacturing processes' selection in the graduation and research projects undertaken by teachers and students. The result, in addition to allowing a deeper analysis on how this field is evolving in this academic institution, is that the Observatory will help define new research guidelines and academic projects related to materials culture studies or technical innovation experiments in the form of a database.
\end{abstract}

Keywords: Material Culture, Observatory, Design, Materials, Innovation 


\section{INTRODUÇÃO}

A motivação para a pesquisa, surgiu a partir de uma demanda institucional para organizar, prover e manter o acervo de materiais reunido pelo grupo de pesquisa "Matéria-prima", em funcionamento no período compreendido entre 2006 a 2009 e do qual uma das autoras participou ativamente. Neste período foi desenvolvida a pesquisa "Cartografia dos materiais: organização, usabilidade e produtos", cujo objetivo principal era "identificar, mapear, organizar e disponibilizar informações sobre os materiais e seus processos de transformação", além de analisar suas aplicações em artefatos e em superfícies (DANTAS, MALAGUTI e CAMPOS, 2008). A premissa que norteou a primeira fase do projeto promoveu a reflexão sobre a destinação do acervo, em busca de iniciativas que viabilizassem a exposição permanente do material e dos resultados das pesquisas para a comunidade acadêmica, favorecendo uma leitura articulada dos conjuntos e unidade, dando suporte a novas pesquisas e projetos na área do design.

O resultado deste esforço foi a concepção e a elaboração de três exposições organizadas pelo grupo de pesquisa. As duas primeiras mostras foram vinculadas ao tema da sustentabilidade - a primeira apresentava diversas amostras de materiais e a segunda, denominada "Cartografias da diversidade", associava recursos naturais, matérias-primas processadas e produtos finais em cadeias produtivas. A terceira exposição reuniu pelo tema "Reflexos e Transparências", materiais diferentes com tais propriedades.

A partir da análise dos resultados das exposições foi possível refletir sobre utilização do acervo para incentivar pesquisas na instituição sobre materiais e seus processos de transformação aplicados em projetos, favorecendo a reflexão sobre a produção de design. Uma das possibilidades verificadas foi a elaboração de um espaço, para expor tanto as amostras como os resultados das pesquisas desenvolvidas sobre a utilização destes materiais, dando suporte às atividades de ensino e pesquisa na instituição, sem esquecer o vínculo com o grupo de pesquisa Cultura e Comportamento, que também envolve estudos sobre o patrimônio cultural, as representações materiais, a construção simbólica da cultura, sobre cultura material. Neste campo é possível articular a discussão teórico-metodológica sobre o projeto de design, que, sem dúvida, inclui a reflexão sobre o uso e a transformação de materiais, sobre processos de produção.

Neste caminho, o projeto "Cultura material e design: observatório de mudanças" (2013-2014) propõe definir diretrizes para implantação de um Observatório de mudanças na cultura material, associadas à utilização de materiais em produtos de autoria atribuída a designers, lançados no mercado nacional, a partir dos anos 1960. O objeto de observação é constituído pelo conjunto de materiais reunidos de 2006 a 2009 e, também, por trabalhos de pesquisa de alunos e professores pesquisadores da instituição nas últimas décadas.

\section{DESENVOLVIMENTO}

Decorrentes da preocupação de incentivar alunos, professores e pesquisadores a investigar materiais e processos de transformação para a produção do design, outras indagações foram importantes para refletir sobre o arranjo do acervo. Alguns aspectos foram levantados, como a organização dos materiais e suas informações; os critérios para o arranjo e para exposição circunstanciada do acervo; o formato e a forma de 
disponibilizar tais informações, de maneira a criar um instrumento de pesquisa para a comunidade acadêmica.

Uma pesquisa exploratória realizada a partir do levantamento de Trabalhos de Conclusão de Curso [TCC], assim como de pesquisas realizadas na instituição no âmbito do Design Gráfico, de Produto e de Moda (Quadro 1), evidenciou o grande interesse entre alunos e professores pelo estudo dos materiais e processos de transformação. Apesar das dificuldades enfrentadas para encontrar informações técnicas adequadas para cada necessidade, os trabalhos contêm informações relevantes, tanto sobre a cadeia produtiva de diversos materiais como sobre especialistas, designers, grupos, instituições e regiões de excelência na área, além de condições de uso, aplicações e produtos típicos, clássicos ou inovadores. No entanto, ainda não existiam informações disponíveis na instituição, que articulassem os conteúdos técnicos de tais trabalhos, bem como o fácil acesso para consulta.

Quadro 1 - Trabalhos de Conclusão de Curso e pesquisas de Iniciação Científica com foco em materiais, desenvolvidos por alunos dos Cursos de Design do Centro Universitário Senac - SP, e orientados pela professora Dra. Cyntia Santos Malaguti de Sousa (2008 a 2013).

\begin{tabular}{|l|l|l|l|}
\hline Pesquisa & Autor & Título & Ano \\
\hline \multirow{4}{*}{$\begin{array}{l}\text { Iniciação } \\
\text { Científica }\end{array}$} & Tissyana Carrião Guimarães & Recursos naturais: usos e novas possibilidades & 2008 \\
\cline { 2 - 4 } & Ana Betty Finkelstein & Dos alimentos às fibras têxteis & 2008 \\
\cline { 2 - 4 } & Gabriela Santos Silvares & $\begin{array}{l}\text { Materiais compostos e compatibilidade } \\
\text { ambiental }\end{array}$ & 2008 \\
\hline \multirow{4}{*}{$\begin{array}{l}\text { Trabalho de } \\
\text { Conclusão } \\
\text { de Curso } \\
\text { [TCC] }\end{array}$} & Raphael Paulo Ciccotti & Biojóia: uma opção natural & 2009 \\
\cline { 2 - 4 } & Amanda Mendes Mandolini de & $\begin{array}{l}\text { Mobiliário para espaços expositivos com } \\
\text { madeira de poda }\end{array}$ & 2011 \\
\cline { 2 - 4 } & Michelle de M. Silva & $\begin{array}{l}\text { Desenvolvimento de produto a base de } \\
\text { compósito de fibra de coco verde e resina } \\
\text { natural }\end{array}$ & 2011 \\
\cline { 2 - 4 } & Marcelo Gustavo Sganzerla & $\begin{array}{l}\text { Fibra de coco: aplicações e potenciais no } \\
\text { design }\end{array}$ & 2012 \\
\cline { 2 - 4 } & Thaís Ayumi Suemazu & $\begin{array}{l}\text { Fibras e laços: intervenção do design e } \\
\text { desenvolvimento local. }\end{array}$ & 2013 \\
\hline
\end{tabular}

Fonte: elaborado pelos autores, com base na pesquisa realizada.

O acompanhamento das motivações dos autores, do processo de pesquisa, das discussões e do desenvolvimento de projetos, nestes e em outros casos, mostrou que cada um delineava redes de conexões que, independente do ponto de partida ou do resultado final alcançado, poderiam gerar cartografias ou infográficos ligando materiais a produtos, enfatizando diversos aspectos como: a história, as questões técnicas e processos de produção, fatores econômicos, socioculturais ou éticos, a responsabilidade ambiental, questões relacionadas à sustentabilidade, à inovação, entre outros.

Verificou-se que as articulações instituídas a partir das conexões entre materiais e produtos, estabeleciam conjuntos de dados relacionados e que poderiam constituir sistemas interligados de informação sobre uso de materiais e processos de fabricação de artefatos. Estas redes, se organizadas a partir de um método comum, poderiam contribuir para a realização de diagnósticos periódicos e na subsequente definição de eventuais diretrizes para o ensino e a pesquisa sobre design, materiais, processos de transformação e de fabricação, assim como auxiliar pesquisadores e 
alunos na construção de novos conhecimentos, com base em estudos desenvolvidos sobre esta temática.

$\mathrm{Na}$ atual fase da pesquisa, a definição de um método foi essencial para disponibilizar as informações sobre cada material do acervo, partindo da ideia de que novos estudos podem complementar tais informações. Assim, a partir do método de organização é possível constituir "mapas" de leitura de cada unidade do acervo. A sobreposição de tais mapas pode gerar diferentes pontos de convergência entre os elementos, permitindo vários tipos de análise e correlações. Para contribuir neste processo, foi necessário refletir sobre o sistema de organização, classificação e catalogação do material do acervo. ${ }^{1}$ A proposta foi ampliar a descrição do acervo a partir de organização multinível do universo pesquisado, inserindo cada item na estrutura geral do fundo, por se tratar de materiais que integram patrimônio privado de caráter permanente (BELLOTO, 2006). O sistema permite descrever as unidades e conjuntos em estrutura hierárquica, mantendo a relação orgânica com a origem do acervo. Também, permite que as informações geradas, a partir de trabalhos e pesquisas sobre processos de transformação e de produção aplicados em projetos de design, possam ser articulados à estrutura permanente do acervo - os materiais.

Outra questão importante para esta pesquisa, como anteriormente mencionado, está relacionada à cultura material, sua definição e a utilização de seus componentes como documentos, como fontes, para estudos sobre história, antropologia, sociologia e no campo do design. Este foi o ponto de partida para estabelecer parâmetros teóricos.

\subsection{Cultura, materialidade e design}

Vários conceitos e teorias sobre cultura têm sido apresentados, a partir de correntes de pensamento que estudam as sociedades e seus fenômenos. Neste artigo adotou-se o conceito semiótico defendido pelo antropólogo Geertz (1989), que considera que a cultura como "sistemas entrelaçados de signos interpretáveis" 2 ". 0 autor admite a cultura como teias de significados e sua análise e, portanto, trata-se de uma ciência interpretativa (GEERTZ, 1989, p.4). Como tal, ela não pode ser compreendida como "um poder, algo ao qual podem ser atribuídos casualmente os acontecimentos sociais, os comportamentos, as instituições ou os processos" (Ibid., p.10). Para Geertz a "cultura é um contexto", no qual os símbolos "podem ser descritos de forma inteligível [...], descritos com densidade" (Ibid.).

Apesar das diferenças existentes entre as várias correntes de pensamento sobre cultura, a maioria delas considera que ela abrange tanto elementos 'imateriais' ação social, hábitos, valores e crenças - quanto 'materiais' - meio físico. O termo cultura material começou a ser empregado no século XIX, no campo da Arqueologia (BUCAILLE e PESEZ, 1989). De acordo com Rafael Cardoso Denis, atualmente o uso do termo estende-se à cultura material produzida nas sociedades e possibilita "uma maneira de entender melhor os artefatos que produzimos e consumimos, bem como a maneira com que estes se encaixam em sistemas simbólicos e ideológicos mais amplos" (DENIS, 1998, p.19-20).

\footnotetext{
${ }^{1}$ Cf. algumas das referências pesquisadas BELLOTO, 2006; TESSITORE, 2003; LOPEZ, 2002; GOLÇALVES, 1998.

${ }^{2}$ Neste trecho, Geertz admite que "signos interpretativos" são símbolos. Cf. GEERTZ, 1989, p.10.
} 
O historiador Ulpiano Bezerra de Meneses define cultura material como "aquele segmento do meio físico que é socialmente apropriado pelo homem" (1983, p.112). Para o autor, verificamos uma apropriação social, quando há intervenção do homem sobre os elementos do meio físico, de acordo com propósitos, normas e padrões de uma sociedade, sem desvincular as ações humanas das esferas política, econômica, social e cultural. ${ }^{3}$ Nesta direção, os elementos do meio físico são componentes da produção e da reprodução da vida social. Assim, os artefatos podem "ser considerados sob duplo aspecto: como produtos e vetores de relações sociais." (Ibid., p.113).

Observou-se nestas definições uma dimensão historiográfica. Neste caminho, a cultura é um contexto e os elementos do meio físico como documentos, que devem ser descritos para identificarmos comportamentos, discursos, processos, eventos, relações sociais, entre outros. Assim, o artefato não deve ser considerado como um objeto inerte, ou como reflexo passivo da dimensão sociocultural, tampouco como fonte que apenas ilustra e comprova a documentação escrita, mas sim como um agente ativo na vida social e no processo cognitivo envolvido nesse contexto. Seu significado reside no próprio objeto, nas suas características, atributos, qualidades físicas, mas também nas ações humanas, em todo contexto que envolve sua produção, o consumo, o uso e, sem dúvida, nas relações sociais que decorrem de todos estes aspectos, em determinado espaço, tempo e grupo social. (Cf. GEERTZ, 1989; MENESES, 1998; PROWN, 1982)

Ao estabelecer uma relação entre design e cultura material Denis salienta que o design, como atividade de projeto que visa "a objetivação no seu sentido estrito, ou seja, dar existência concreta e autônoma a idéias abstratas e subjetivas" (1998, p. 19) origina artefatos que, considerados como um determinado conjunto produzido ou utilizado por grupo ou sociedade, constituem parte significativa da cultura material desse grupo ou sociedade. Para o autor, a partir da Revolução Industrial o design progressivamente tornou-se "um sítio privilegiado para a geração de artefatos" tratando-se, atualmente, do "foro principal para o planejamento e o desenvolvimento da maioria quase absoluta dos objetos que constituem a paisagem artificial" no universo dos bens móveis (Ibid., p. 22). E pelo fato da sociedade ocidental contemporânea pautar sua identidade cultural na abundância material por ela gerada, o design configura-se como uma das fontes importantes de informação sobre essa cultura, seja em estudos históricos, diagnósticos ou até prospectivos. Sem dúvida, esta visão reafirma a dimensão historiográfica da cultura material.

Para esta pesquisa, interessava relacionar matérias-primas e objetos, levando em conta trabalhos acadêmicos e pesquisas realizadas na instituição, que evidenciassem a seleção, por parte de seus autores, de materiais brutos e naturais e/ou de matérias convertidas e processadas, assim como técnicas, processos de transformação e os resultados materializados em experimentações ou projetos de artefatos. Partiu-se do princípio que as opções, os partidos de projeto adotados pelos autores (alunos, professores orientadores e pesquisadores) refletem suas consciências e as visões de mundo destes autores. Em outras palavras: "ao realizar o ato de projetar, o indivíduo que o faz não somente projeta uma forma ou um objeto, mas,

\footnotetext{
${ }^{3}$ É importante mencionar que, para Ulpiano (1983), o campo de estudo da cultura material abrange, além dos artefatos, estrutura, ações sobre a paisagem e natureza, o corpo quando consideramos manipulações sobre ele ou caracterizações em arranjos em espaços.
} 
necessariamente, também se projeta naquela forma ou naquele objeto" (DENIS, 1998, p.37). Nesta perspectiva, analisando tais trabalhos e pesquisas, pode-se observar tanto valores, anseios e crenças que motivaram os autores, quanto métodos e fontes de inspiração utilizados.

\subsection{Design, áreas e categorias de artefatos}

Retomando a abordagem sobre métodos de arranjo, descrição e exposição do acervo, foi necessário adotar critérios para a classificação não apenas dos materiais, mas também dos processos de transformação e produção, bem como de classificação dos projetos de design.

Uma das questões levantadas na pesquisa foi a divisão das áreas ou subáreas de interesse ou campos de atuação dos designers. De fato, a atividade profissional nos vários campos do design - produto, gráfico, digital e moda, apenas para citar as áreas formação oferecidas nesta instituição - não são estanques, não estabelecem fronteiras que impeçam a interdisciplinaridade. Isto pode ser verificado em diversas esferas como a educação, as associações de classe, o mercado de trabalho, o setor econômico e as políticas governamentais.

Levando em conta a formação na área do design, o Ministério da Educação considera leis e instrumentos que regulamentam o Ensino Superior no Brasil e o sistema de avaliação da qualidade de ensino, seguindo as metas estabelecidas no Plano Nacional de Educação (2001). A legislação e as recomendações tendem à generalização na formação dos profissionais da área. Para exemplificar, podemos citar o documento Referenciais Curriculares Nacionais dos Cursos de Bacharelado e Licenciatura $(2010)^{4}$, criado para sistematizar a nomenclatura e sintetizar um perfil de formação, conferindo certa "identidade" para cada curso superior, acompanhando a proposta das Diretrizes Curriculares Nacionais dos Cursos de Graduação. O documento recomenda a convergência de denominação dos cursos ofertados, com lista de sugestões de nomes adotados e cadastrados pela Secretaria de Educação Superior, além de estabelecer o perfil do egresso, as temáticas a serem abordadas durante a formação, uma visão ampla sobre o campo de atuação do profissional formado e a infraestrutura recomendada para a oferta dos cursos.

$\mathrm{O}$ documento estabelece nomenclatura única para o bacharelado na área (Ibid., p.6) - DESIGN - e temas gerais para a formação, que podem ser adequados de acordo com a linha de formação dos cursos ofertados nas instituições, a exemplo de Métodos e Técnicas de Projetos; Materiais e Processos de Fabricação; Meios de Representação; Relações Ciência, Tecnologia e Sociedade, entre outros. O mesmo documento, porém, admite algumas áreas de atuação dos profissionais formados no ensino superior: "pesquisador em Instituições de Ensino Superior, empresas e laboratórios de pesquisa científica e tecnológica; em gráficas e editoras; em escritórios de Design; na produção industrial (automobilística, eletroeletrônicos, embalagens de produtos, logomarcas, mobiliário, joalheria, calçados, vestuário, entre outras); em empresas de comunicação visual. Também pode atuar de forma autônoma, em empresa própria ou prestando consultoria." (BRASIL. MEC / SESu, 2010, p.28).

No portal Design Brasil, a seção Design Made in Brazil dá acesso à página Escritórios de Design, que disponibiliza sistema de busca de profissionais cadastrados.

\footnotetext{
${ }^{4}$ BRASIL. Ministério da Educação. Secretaria de Educação Superior. Referenciais Curriculares Nacionais dos Cursos de Bacharelado e Licenciatura. Brasília: MEC, SESu, 2010.
} 
O formulário permite a seleção das seguintes áreas de atuação: ambientes, branding, digital, embalagens, gráfico, moda, móveis, políticas de design, produtos, serviços. Há também formulário para o cadastro de escritórios prestadores de serviço na área apenas pessoa jurídica - nas mesmas áreas. ${ }^{5}$

O mesmo portal publicou, no início de novembro de 2013, matéria intitulada "Quantos escritórios de design existem no Brasil?", para divulgar pesquisa de mesmo nome. A publicação faz parte de uma ação do Ministério do Desenvolvimento, Indústria e Comércio Exterior, MDIC, em parceria com a Agência Brasileira de Promoção das Exportações e Investimentos, Apex-Brasil. Uma das propostas do estudo citado é levantar dados e informações sobre o campo do design no país, mapeando agentes e instituições ligadas à produção formal nesta área (BAUER, 2013, online). Faz parte da base de dados para este estudo um cadastro de escritórios de design disponibilizado no portal Design Brasil. No formulário verificamos os "segmentos de atuação" disponíveis: Design gráfico/comunicação; Design de interiores; Design de produto/desenho industrial; Design digital/web/multimídia; Design de moda; Design de serviços.

Apesar do Ministério da Educação buscar a generalização para a formação na área de design, o levantamento de entidades e órgãos relacionados à pesquisa ou ao campo profissional comprovou que é necessária a identificação das subáreas, para caracterizar as especificidades dos projetos de design e suas aplicações no mercado, mesmo porque os substratos utilizados para o processo de produção nestes campos de trabalho são substancialmente diferentes, o que, é certo, pode determinar de maneira decisiva a reflexão sobre o processo de design e a seleção de partidos de projeto. ${ }^{6}$

Levando em conta a pesquisa proposta e a necessidade de relacionar materiais, técnicas, processos, projeto, buscou-se, também, investigar bases de dados ou acervos disponibilizados on-line, utilizados como referências para pesquisas e projetos, do ponto de vista da relação criada entre artefatos, materiais e processos.

\subsection{A relação entre materiais e design em acervos online}

Foram selecionados para análise, num primeiro momento, duas associações de classe que representam a atuação profissional nas duas áreas Design de Produto e Design Gráfico - Associação dos Designers de Produto, ADP e a Associação dos Designers Gráficos do Brasil, ADG-BR. Levantou-se também 5 premiações da área Prêmio Design do Museu da Casa Brasileira, Idea Brasil, Prêmio Brasileiro de Excelência Gráfica Fernado Pini, Prêmio ABRE da Embalagem Brasileira, if Design Awards -, duas materiotecas - Laboratório de Materiais da Universidade Feevale e MateriaBrasil -, além de um museu virtual, A Casa - Museu do Objeto Brasileiro. A escolha observou a atuação consolidada e reconhecida destas referências, que são utilizadas como fonte de pesquisa em trabalhos acadêmicos.

\footnotetext{
${ }^{5}$ Cf. http://www.designbrasil.org.br/escritorios-de-design/. Acesso em: jan. 2014.

6 Podemos exemplificar citando as áreas do conhecimento estabelecidas pelo Conselho Nacional de Desenvolvimento Científico e Tecnológico, CNPq: o design pertence à área das Ciências Sociais Aplicadas, é identificado como Desenho Industrial e abrange duas subáreas: a Programação Visual e o Desenho de Produto. Cf.: http://www.cnpq.br/documents/10157/186158/TabeladeAreasdoConhecimento.pdf. Acesso em nov. 2013. As associações de classe no Brasil também representam os profissionais das subáreas Produto e Gráfico: Associação dos Designers de Produto, ADP e a Associação dos Designers Gráficos do Brasil, ADG-BR.
} 
A Associação dos Designers de Produto [ADP] brasileira em parceria com o Ministério do Desenvolvimento, Indústria e Comércio Exterior, por meio do Programa Brasileiro de Design, com o intuito de medir e avaliar a importância estratégica do design para a competitividade das empresas tanto no mercado nacional como no exterior, idealizaram uma pesquisa - realizada pela Fundação Getúlio Vargas - que abrange 10 setores industriais: moveleiro, utensílios domésticos, automobilístico, equipamentos desportivos, eletroeletrônicos, eletrodomésticos, moda e acessórios, máquinas operatrizes, equipamentos médico-hospitalares, materiais de construção.

A Associação dos Designers Gráficos do Brasil [ADG-BR] organiza o evento Bienal Brasileira de Design Gráfico desde 1992, que tem como proposta apresentar e mapear a produção de design gráfico nacional, selecionando destaques. 0 regulamento da 10a edição (2013) admite a inscrição de trabalhos realizados por empresas da área e profissionais. Também é possível a participação de estudantes, que podem inscrever projetos de graduação. No regulamento observamos 8 categorias que apresentam subdivisões de acordo com o projeto inscrito: Identidade \& Branding; Impressos Editoriais; Impressos Promocionais, Digital, Espacial, Embalagens, Tipografia e Fronteiras, que inclui projetos gráficos desenvolvidos para produtos, moda, ilustração, arte. ${ }^{7}$

Um dos principais concursos da área no Brasil, o Prêmio Design Museu da Casa Brasileira [MCB] é anual, realizado pelo Museu e promovido pela Secretaria de Estado da Cultura de São Paulo. O Prêmio Design é aberto para inscrição de produtos em produção ou protótipos e a produção teórica nas áreas de design gráfico, design de produto, arquitetura, urbanismo e paisagismo. De acordo com o regulamento da 27 a edição do prêmio (2013), a premiação de design de produtos, já em linha de produção ou ainda em fase de projeto apresentados como protótipos, abrange 7 categorias: Mobiliário, Utensílios, Iluminação, Têxtil, Equipamentos Eletroeletrônicos, de Construção e de Transporte. ${ }^{8}$ As categorias são muito próximas dos setores industriais apontados na pesquisa da ADP.

Outro importante concurso para a área do design no Brasil é o Prêmio IDEA/Brasil, versão do prêmio IDEA Awards realizado nos Estados Unidos. No Brasil o prêmio é promovido pela ApexBrasil e Objeto Brasil, com endosso da Industrial Designers Society of America, IDSA. O prêmio brasileiro é divido em 24 categorias, em certa ordem muito semelhantes ao iF Product Design Award. A subdivisão privilegia o local e função de uso do produto, a exemplo de categorias como Entretenimento; Banheiros, Spas, Bem-Estar; Sala de Estar e quartos. Também inclui grandes segmentos de mercado como produtos produzidos para o setor da comunicação, e a categoria Comércio e Industriais, que abrange Equipamentos e Sistemas de construção, Mobiliário Industrial, Acessórios e Iluminação, Máquinas Pesadas, Conceitos e Protótipos.

$\mathrm{Na}$ área gráfica as categorias, em geral, segmentam a atuação profissional em subáreas do design gráfico, notadamente a prestação de serviços, o que pode incluir segmentos de mercado dos setores econômicos, a exemplo o trabalho realizado para o campo da comunicação, para editoras ou a produção de embalagens. Isto pode ser

\footnotetext{
${ }^{7}$ Regulamento da 10a Bienal Brasileira de Design Gráfico, disponível em http://www.bienaladg.org.br/, acesso em nov. 2013.

8 Regulamento para o 270 Prêmio Design Museu da Casa Brasileira, 2013. Disponível em: http://www.mcb.org.br/, acesso em nov. 2013.
} 
observado tanto no Regulamento da 10a Bienal Brasileira de Design Gráfico, como nas premiações levantadas da área: o 23 Prêmio Brasileiro de Excelência Gráfica Fernando Pini e o Prêmio Abre da Embalagem Brasileira, promovido pela Associação Brasileira de Embalagem. ${ }^{9}$

O if Design Awards, concurso internacional formado por três prêmios, considera 3 grandes áreas do design - produto, embalagem e comunicação. A edição 2014 do if Product Design Awards abrangeu 17 categorias: Transportes/Veículos Especiais; Lazer/Estilo de Vida; Áudio/Vídeo; Telecomunicações; Computadores; Escritório/Empresa; Iluminação; Sala de Estar/Dormitório; Cozinha; Produtos para Casa/Talheres; Banheiro/Bem-Estar; Construções; Design Público; Medicina/Saúde; Indústria/Comércio; Materiais/Têxtil/Revestimentos; Pesquisa e Desenvolvimento/ Conceitos Profissionais. O prêmio iF Packaging Design Award 2014 abrange todos os tipos de embalagens, sistemas de acondicionamento e acessórios para embalagens, que podem ser inscritos nas categorias: Bebidas; Alimentação; Beleza/Saúde/Casa; Lazer/Estilo de vida; Eletrônicos; Formato da Embalagem; Pesquisa e Desenvolvimento/Conceitos Profissionais. Para o if Communication Design Award 2014 o regulamento apresenta as categorias: Mídia Digital; Mídia Impressa; Interface de Produtos; Crossmedia; Arquitetura Corporativa/Design de Interiores, além da categoria Pesquisa e Desenvolvimento/Conceitos Profissionais. ${ }^{10}$

Observando os sites que apresentam premiações, embora com formatações levemente diferentes, suas coleções são organizadas por edição/ano da edição (premiação), categoria de uso dos objetos e nível/tipo de premiação, que também são indexadores para a busca e pesquisa possíveis. O memorial descritivo de cada produto premiado o identifica pelo nome e autoria, e contém informações sobre as motivações e os objetivos do projeto, materiais e processos de produção empregados, além de seus aspectos distintivos de inovação e resultados de configuração e desempenho alcançados. Ao analisar estas iniciativas, sem dúvida, percebe-se um esforço de síntese que estabelece relações fundamentais entre materiais, processos e o produto final. No entanto, as informações são apresentadas em texto corrido, sem hierarquia ou ordem de descrição dos atributos ou características dos produtos, materiais e processos de fabricação, em diferentes estilos.

As bibliotecas sobre materiais propõem outra abordagem, partindo do próprio material. O Laboratório de Materiais - Materioteca da Universidade Feevale, Novo Hamburgo - RS, é vinculada a um curso de graduação em design, localizando-se no Centro de Design da Universidade, onde está disponível para consulta (alunos, professores e interessados, sem restrições) um acervo físico de amostras (produtos e materiais) e virtual sobre materiais e amostras relacionadas. ${ }^{11}$

A MateriaBrasil, com sedes em São Paulo e no Rio de Janeiro, originária de uma parceria entre duas empresas, Fibra e Sistema Ambiental, funciona como uma consultoria independente. Apresenta-se como um "Centro de Referência" em inovação

\footnotetext{
9 Regulamento do 23ㅇ Prêmio Brasileiro de Excelência Gráfica Fernando Pini, disponível no site da Associação Brasileira de Tecnologia Gráfica, http://www.abtg.org.br/, acesso em nov. 2013. Regulamento do Prêmio Abre da Embalagem Brasileira, disponível em http://www.premioabre.org.br/, acesso em set. 2013.

10 Os regulamentos são disponibilizados para download em http://www.ifdesign.de/, acesso em ago. 2013.

${ }^{11}$ Disponível em: http://materiotecafeevale.wordpress.com/, acesso em jun. 2013.
} 
e sustentabilidade que abrange, entre outras atividades, a construção e difusão de conhecimentos (Matéria Saber) de forma colaborativa, por meio de uma materioteca, cursos e eventos. A MateriaBrasil dispõe de acervo físico e virtual, porém, no site é necessário um cadastro, que requer login e senha, para obter acesso aos fornecedores dos materiais disponibilizados para a consulta no site. ${ }^{12} \mathrm{O}$ acesso disponibilizado pela MateriaBrasil para usuários não cadastrados se dá na modalidade "explore", que não permite buscas nem apresenta qualquer tipo de correlação entre os materiais disponíveis no acervo. Porém, as informações sobre as características e atributos dos materiais é detalhada, em especial as características e os aspectos relacionados aos princípios de sustentabilidade.

A consulta à materioteca da Feevale permite buscas a partir vários filtros, tais como classe de material, característica e empresa, para amostras; e classe de material, nome comercial, processos, meio e desempenho, para materiais. As informações para pesquisa são dispostas em formato de formulário. Os filtros, combinados, estabelecem diversos conjuntos, tanto de materiais como de amostras. Também, é possível relacionar as duas bases virtuais.

Verificou-se que nenhuma das bases mencionadas relaciona materiais e processos a projetos de design específicos. Na materioteco da Feevale, por exemplo, as amostras de produtos apenas ilustram o emprego dos materiais, sem identificar autoria ou descrever eventuais critérios e partidos de projeto adotados para escolha de materiais e processos.

O site de A Casa - Museu do Objeto Brasileiro, ${ }^{13}$ organiza o acervo de objetos por coleções e por arquivo de objetos independentes, que constituem as duas formas iniciais de busca. As coleções reúnem conjuntos de criações de designers, desenvolvidos para projetos e iniciativas do próprio Museu (entre as quais premiações de design), ou ainda de regiões ou comunidades específicas, apresentados sequencialmente. O link "ARQUIVO" admite buscas por palavras-chave ou ainda por autores, eventos ou "assunto", classificados como: artesanato, artesanato contemporâneo, design, eventos, localização geográfica, manifestação cultural, material, objetos, organizações, pessoas e técnica. A seleção dos termos artesanato, artesanato contemporâneo, design direciona para sequencias de imagens de objetos. Os demais permitem uma busca mais refinada, levando a uma relação hierarquizada das subcategorias indexadas naquele "assunto". Percebe-se pela organização das informações um esforço claro para relacionar materiais e processos ao objeto. Além de identificar e caracterizar o objeto, a autoria, forma, dimensões e materiais constitutivos, recupera parte da história do processo de criação, informando como os materiais participaram das motivações iniciais de projeto. Também descreve o processo produtivo empregado, possibilitando o acesso a aspectos técnicos e eventuais inferências sobre diferenciais e inovações alcançadas, o que se complementa com informações sobre premiações obtidas e a avaliação do júri.

O site A Casa segue uma proposta que busca relacionar materiais, processos e design pela cultura material. Porém, a possibilidade de cruzamentos de informações é limitada, dificultando sua utilização para estudos transversais. Deve-se ressaltar, no entanto, o uso de alguns termos que classificam alguns artefatos, levando em conta,

\footnotetext{
12 Disponível em: http://materiabrasil.com/explore, acesso em jun.2013.

${ }^{13}$ Disponível em: http://www.acasa.org.br/, acesso em jun. 2013.
} 
aparentemente, o processo de produção artesanal ou industrial como uma qualidade ou atributo do produto apresentado, sem esclarecer o critério de classificação.

\subsection{Diretrizes para a concepção de um observatório de design}

O termo observatório, de acordo com o Dicionário Houaiss (2001) é definido como o "lugar de onde se observa qualquer coisa; mirante ou miradouro", em geral, criado e gerenciado por um organismo. Sua origem parte da identificação de "uma problemática que possa ser traduzida sob a forma de objetivos, que permitam definir indicadores, cujo cálculo necessita a integração de dados e permita a realização de sínteses" (SESI/SENAI/IEL, 2014, online). O conceito pressupõe o trabalho coletivo, multidisciplinar e diversidade de visões sobre a realidade e para a organização sistemática e para a construção de conhecimento. Muitas vezes se constitui, inicialmente como "núcleo de pesquisa que pode se converter num instrumento de informação e de suporte à decisão pública, potencializando a investigação, a socialização da informação e do conhecimento" (USC, 2014, online). Tais concepções atenderam aos propósitos do estudo aqui apresentado. Assim, o que se pretende implementar é este "lugar" de observação, dotado de dispositivos e métodos, que permitam acompanhar o desenvolvimento de pesquisas e de projetos realizados pela comunidade acadêmica desta instituição de ensino. A proposta é conceber este espaço, que será construído e ampliado progressivamente, com o trabalho coletivo, admitindo múltiplos olhares sobre esta produção. O intuito é que o observatório possa se transformar num instrumento de informação, que potencialize a construção e a socialização do conhecimento.

Para estabelecer as diretrizes do observatório foi necessário pesquisar obras desenvolvidas por designers, cujo enfoque privilegiasse a articulação entre materiais, processos, projetos e objetos exemplares de design. Destacaram-se os trabalhos pioneiros de Manzini (1993) e Ashby (2002), que influenciaram diversas pesquisas e iniciativas, inclusive no Brasil, como se observa em Tonicelo e Antunes (2006), Walter (2006), Faller (2009), autores que contribuíram para o desenvolvimento desta fase da pesquisa.

Manzini (1993), que reverencia a importância histórica do trabalho sobre cultura material e sua relação com os materiais e técnicas do antropólogo LeroiGourhan, ressalta que o fluxo de informações é inerente à atividade do designer e que, sobre este fluxo, ele introduz sua capacidade de prefiguração e de invenção. As novas qualidades da matéria no mundo contemporâneo e a falta de instrumentos interpretativos adequados, no entanto, fazem com que este potencial não seja aproveitado, mesmo que seja ilusório pensar a possibilidade de atingir uma inteligibilidade total sobre um universo tão abrangente e complexo. Assim, para ele "qualquer abordagem da realidade que queira apresentá-la de maneira compreensível deverá recorrer à utilização de um filtro, um modo de organizar a informação bruta de acordo com um modelo apropriado ao tipo de informação que se pretende obter" (MANZINI, 1993, p. 61). Esta organização sugerida por Manzini, foi a inspiração para se pensar em representações gráficas - cartografia - que apresentem ou proponham articulações entre materiais, processos, tecnologias e a concepção de artefatos, ou a reorganização de áreas especializadas, de acordo com sua função no processo do design, de modo a subsidiar tomadas de decisão. 
Tanto as fontes pesquisadas sobre cultura material e suas relações com design quanto a análise dos bancos de dados online aqui mencionados forneceram algumas pistas sobre uma possível estrutura para o desenvolvimento desta cartografia.

Nas referências pesquisadas, em especial nas abordagens relacionadas à sustentabilidade, observa-se a preocupação em apresentar o ciclo de vida dos produtos - do berço ao túmulo, mas nem sempre possibilita uma compreensão da complexidade que ocorre entre as fases de extração de materiais e sua conformação em produtos. No entanto, ao tratar o material de forma genérica, incorrem no risco de representar de forma muito simplificada o percurso após a incorporação do material em um produto, pois outros materiais, processos e variáveis de uso não são considerados.

Observou-se que os diagramas não dão conta de um aspecto fundamental para esta pesquisa: o processo aplicado ao projeto. As melhores referências identificadas até o momento foram encontradas nos trabalhos de Walter (2006, apud BEZOOYEN, 2005) e Ashby e Johnson (2002). As representações demonstram que a seleção de materiais não é feita pontualmente numa fase definida do processo de criação de um novo produto, mas dialoga com ele, num ciclo de atividades não necessariamente linear. O diagrama apresentado por Ashby e Johnson (p.120) é uma ferramenta de apoio à seleção de material para projetos de design. Articula 6 bases de dados: produtos (nome, fabricante, ficha técnica com código do modelo, desempenho, preço); materiais, processos, que descrevem a fisiologia do produto; configuração, percepções - que determinam a psicologia do produto; e intenções - que apresenta as prioridades estabelecidas pelo designer e indicam a personalidade planejada para 0 produto. A principal questão deste instrumento é o fato de ter sido concebido para privilegiar a escolha do material.

\section{CONCLUSÃO}

Como mencionado no item anterior, os diagramas levantados não dão conta do processo aplicado ao projeto. Os diagramas de Walter (2006, apud BEZOOYEN, 2005) e Ashby e Johnson (2002) servirão de base para a construção de representação gráfica, que facilite a apresentação de informações articuladas para pesquisa sobre uso de materiais, processos e técnicas, para além da seleção de materiais, como verificamos a ênfase do trabalho de Ashby e Johnson.

Para a pesquisa em andamento, a ideia é, como mencionado, apresentar as informações articuladas, criando alguns filtros, contribuindo para que os pesquisadores e estudantes encontrem conexões entre elementos, aspectos, fases e processos, de acordo com interesse específico ou relevância para o estudo ou projeto desenvolvido, buscando ampliar perspectivas quanto ao uso de materiais, de processos, técnicas. De igual maneira, possibilitar a identificação de projetos e soluções documentadas que podem servir como ponto de partida para a construção de novas ideias e do conhecimento.

A macroestrutura do observatório ainda não foi definida. As discussões aqui apresentadas expressam apenas os resultados preliminares de uma pesquisa em andamento. Os próximos passos incluem intercâmbios com alguns museus de design, materiotecas, arquivos de cultura material contemporânea e uma análise mais ampla de alguns projetos de graduação e pesquisas, a fim de compreender os processos de decisão e partidos que determinam a escolha e a pesquisa sobre materiais. Estão em 
desenvolvimento os instrumentos que devem sustentar a taxonomia. Estas informações servirão de base para a concepção dos mapas.

Trata-se de uma tarefa complexa, mas espera-se que uma versão piloto possa contribuir para a compreensão sobre a estreita relação entre design e cultura material.

\section{REFERÊNCIAS}

ASHBY, Mike and JOHNSON, Kara. Materials and design: the art and Science of material selection in product design. Oxford: Elsevier, 2002.

BAUER, Juliana. Quantos escritórios de design existem no Brasil? Portal Design Brasil, 01/11/2013. Disponível em: <http://www.designbrasil.org.br/noticias/quantosescritorios-de-design-existem-no-brasil\#.Unu8uHDBOGM>. Acesso em set. 2013. BENOÎT, Catherine and MAZIJN, Bernard (ed.). Guidelines for social lifecycle assessment of products. Belgium: United Nations Environmental Programme, 2009. BELLOTO, Heloísa Liberalli. Arquivos permanentes: tratamento documental, 4.ed. Rio de Janeiro: Editora FGV, 2006.

BUCAILLE, Richard e PESEZ, Jean-Marie. Cultura material. In: Enciclopédia Einaudi, v. 16. Homo - Domesticação - Cultura Material. Lisboa: Imprensa Nacional, 1989. p.1147.

DANTAS, Denise, MALAGUTI, Cyntia e CAMPOS, Ana Paula de. Cartografia dos Materiais: organização, usabilidade e produtos. Etapa IV - 2009 / 2010. Plano de trabalho submetido ao Centro Universitário SENAC para o desenvolvimento de pesquisa institucional. São Paulo: Senac, 2008.

DENIS, Rafael Cardoso. Design, cultura material e o fetichismo dos objetos. In: Revista Arcos. Design, cultura material e visualidade, Rio de Janeiro, v. 1, número único, p. 1439, out. 1998.

DOHMANN, Marcus. A experiência material: a cultura do objeto. Rio de Janeiro: Rio Books, 2013.

FALLER, Roberto da Rosa. Engenharia e design: contribuição ao estudo da seleção de materiais no projeto de produto com foco nas características intangíveis. Dissertação de mestrado. Porto Alegre: UFRGS, 2009.

GEERTZ, Clifford. A interpretação das culturas. Rio de Janeiro: LTC, 1989.

GONÇALVES, Janice. Como classificar e ordenar documentos de arquivo. São Paulo: Arquivo do Estado, 1998.

LOPEZ, André Porto Ancona. Como descrever documentos de arquivo: elaboração de instrumentos de pesquisa. São Paulo: Arquivo do Estado, Imprensa Oficial, 2002.

MANZINI, Ezio. A matéria da invenção. Porto: Centro Português de Design, 1993.

MENESES, Ulpiano T. Bezerra de. A cultura material no estudo das sociedades antigas. Revista de História, São Paulo, n. 115, p. 103-117, 1983.

. Memória e cultura material: documentos pessoais no espaço público.

Revista Estudos Históricos, Rio de Janeiro, v. 11, n. 21, p. 89-104, 1998.

ONO, Maristela Mitsuko. Design e cultura: sintonia essencial. Curitiba: edição da autora, 2006.

PROWN, Jules David. Mind in Matter: An introduction to material culture theory and method. Winterthur Portfolio. V. 17. N. 1 Chicago: Henry Francis du Pont Winterthur Museum / The University of Chicago Press. (Spring, 1982). p. 1-19. Disponível em: 
<http://www.jstor.org/discover/10.2307/1180761 ?uid=2\&uid=4\&sid=2110301245421 7>. Acesso em: jan. 2014.

SESI/SENAI/IEL. O que é um observatório? Observatórios. Disponível em: <http://www.fiepr.org.br/observatorios/FreeComponent2272content11361.shtml>. Acesso em: fev.2014.

TESSOTORE, Viviane. Como implantar centros de documentação. São Paulo: Arquivo do Estado, Imprensa Oficial, 2003.

TONICELO, Roberta Helena dos Santos e ANTUNES, Douglas Ladik. Estudo dos materiais a partir de seus ciclos de vida: um olhar sobre as conseqüências ambientais de seus empregos no design. DAPesquisa - Revista de investigação em artes. Design, Florianópolis, v.2, n.1, 2005-2006. Disponível em: <http://www.ceart.udesc.br/revista_dapesquisa/volume2/numero1/design/artigo.mat erioteca.pdf>. Acesso em: fev. 2014.

UCS. Quem somos. NID - Observatório de Educação. Disponível em: <http://www.ucs.br/site/nucleos-pesquisa-e-inovacao-e-desenvolvimento/nucleos-deinovacao-e-desenvolvimento/observatorio-de-educacao/>. Acesso em: fev. 2014.

WALTER, Yuri. $O$ conteúdo da forma: subsídios para seleção de materiais e design. Dissertação de mestrado. Bauru: FAAC/UNESP, 2006. 